\title{
"A Van with a Bar and a Bed": Ritualized Gender Norms in the John/Joan Case
}

\author{
John M. Sloop
}

Through a critical reading of the mass mediated discourse that arose in the wake of the John/Joan or "twins" case, this analysis investigates contemporary iterations of gender performativity, gendered morals and feminism. The author calls for a complication of gender culture and feminism in the public sphere. Keywords: gender, performativity, heteronormativity, feminism

There is a tendency to think that sexuality is either constructed or determined; to think that if it is constructed, it is in some sense free, and if it is determined, it is in some sense fixed. These oppositions do not describe the complexity of what is at stake in any effort to take account of the conditions under which sex and sexuality are assumed. The 'performative' dimension of construction is precisely the forced reiteration of norms."

Judith Butler, Bodies That Matter (94-5)

We define bodies in the first place only when we are conflicted, as a society and often within ourselves.

Alan Hyde, Bodies of Law (11)

$\mathrm{I}^{\mathrm{N}}$

$\mathrm{N}$ mid-March 1997, a radio report told the story of a male infant whose penis had been excised as the result of an accident during a circumcision procedure. In consultation with physicians, the parents requested that the child, after additional surgery and ongoing hormone therapy, be "reassigned" as female. ${ }^{1}$ The news reporter observed that the case, which came to be known as the John/Joan case after the child's female and male pseudonyms, was especially interesting because the child-then reassigned a young girl-had a twin brother and hence had been used by medical psychologist John Money as a case study of the social constructedness of gender. ${ }^{2}$ Indeed, because Money repeatedly reported in both the popular and medical press on the success of the reassignment, the case had been pointed to for years as key evidence by those holding a social construction view of gender.

However, the report went on, a recent article in a medical journal was claiming that the child had never comfortably accepted the reassignment and had in fact actively resisted living as a girl. Finally being told as a teenager that "she" was originally a boy, the youth made an immediate decision to be surgically and socially reassigned once again, this time as male. The report implied that, because the John/Joan case had been lauded for years as compelling evidence of gender's constructionism, the discovery of the eventual outcome of the case was evidence that theories of constructionists were wrong-gender was instead essentially determined by the body. Indeed, over the next several days and months, reports in multiple publications, with headlines such as "Sexual Identity Not Pliable After All, Report Says" (Angier A1), "Rethinking Gender Identity" (MacLean's 31), and "The Basis of Sexual Identity" (Roan E1), drew the conclusion that gender is not primarily a 
matter of social condition but rather a matter of biologically determined impulses. The case was said to illustrate that "The experts had it all wrong" (Gorman 83). As Time put it, gender is a matter of the "brain" rather than of cultural conditioning, of natural imperatives rather than of cultural roles and social conditioning. ${ }^{3}$

As the case continued to unfold in academic and trade journals, the arguments consistently illustrated the lack of complexity that Judith Butler points to in the quotation opening this essay. Indeed, what debate there was on the case posited it in the starkly contrasting terms of gender as purely social, or of gender as essentially tied to the body's given sex, with the "determined" side of the binary posited as clearly winning the day. As Lauren Berlant might note of this case, the tension that it illustrates around gender "reveals a desire for identity to be ontological, dead to history, not in any play or danger of representation, anxiety, improvisation, desire or panic" (72).

In her well known deconstruction of the sex-gender (essentialism-constructionism) binary (and the complication of gender as performative), Judith Butler provides a lens through which to complicate the scientific and public arguments that took place around the body and activities of John/Joan. As Butler notes, the problem with the sex-gender division is that it establishes the sexed body as "natural," existing prediscursively, prior to culture, "a politically neutral surface on which culture acts" (Gender 7). While Butler argues that "sex" can never be prediscursive and thereby never be either apolitical or determinate, she also argues against seeing gendered behavior as freely open for play by any individual. Rather, to posit gender and gender behaviors as performative is to see it as "a ritualized production, a ritual reiterated under and through constraint, under and through the force of prohibition and taboo, with the threat of ostracism [...] compelling the shape of the production, but not [... .] determining it fully in advance" (Bodies 95). As a result, the project of a political genealogy of gender becomes one of noting the forces that turn contingent acts into naturalistic necessities, and of noting how various possibilities for different gender behaviors "have been forcibly foreclosed by the various reifications of gender that have constituted its contingent ontologies" (Gender 33).

As I will show, the arguments surrounding the John/Joan case-a case which had the potential to cause "gender trouble" by "subverting and displacing those naturalized and reified notions of gender that support masculine hegemony and heterosexual power" (Butler Gender 33)-illustrate the disciplinary power of the ritualized production of gender regardless of the "gender theory" held by those arguing. That is, while some observers and figures involved in the case treat John/Joan's physical appearance and behaviors primarily as biological signs of sex, and others treat these same appearances and behaviors as contingent signifiers, both rely so uniformly on the same signifier-signified relations that they become crystallized as natural signs. In short, even if one deconstructs the sex-gender differentiation with Butler on a theoretical level, arguments over the case provide a body of public and scientific discourse which consistently offers ritualized reiterations of a binaristic system of sex-based, male-female differences. To put this in the words of Judith Halberstam, rather than naively celebrating gender fluidity, we need to begin to talk again "about the ways in which desire and gender and sexuality tend to be remarkably rigid" (290).

Hence, rhetorically and culturally, the public discussion of the case creates a complex body of discourse that calls for critical attention, especially by gender critics 
who hold a performative position. This case, a case which held the potential to problematize naturalized categories that tie gender to sex, consistently worked instead to reify binaristic expectations of gendered behavior. In effect, both those positing gender as constructed and those who posited sex as natural (or at least primarily determinate) used the same evidence, the same set of signifiers, to support their arguments on John/Joan's success/failure in fitting his/her gender role. These signifiers make up a portion of what Sabrina Petra Ramet refers to as gender culture: "a society's understanding of what is possible, proper, and perverse in gender-linked behavior" (2). ${ }^{4}$ Moreover, these signifiers are the same "forced reiteration of norms" (Butler Bodies 94) that we all face-the same reiterations that impel and sustain our own gender performances.

In the following sections of this essay, I provide a reading of the John/Joan case as it was reported in "scientific" and mass media print outlets. ${ }^{5}$ By looking at both sets of discourses (from 1969 to the present), I develop a critical reading of the evidence of proper gender behavior utilized in medical journals and will note the types of evidence that signal key public understandings of gender behavior as they become translated and crystallized in popular news magazines and newspapers. First, I argue that, for both those who discuss the case publicly from a constructivist position and those who hold that gender is primarily an expression of the body's sex, ${ }^{6}$ gender is seen as being successfully or unsuccessfully behaved/expressed through particular uses of clothing, hair style, body orientation (notably during urination), and physical activities. It is these activities which make up in large part the reiteration of gender norms. Secondly, I discuss specific ways that the case articulates a link between successful gender behavior and heterosexual desire. Third, I discuss the social and moral implications of the bio-basic gender ideology implied by the contemporary public arguments of the John/Joan case (i.e., one cannot successfully work against one's biological gender impulses). Finally, as a related issue, I discuss the problematic ways that feminism and women's studies are constructed by observers of the case, the ways in which "feminism" is itself articulated with a particular view of gender. In short, I am interested in investigating and "troubling" the way gender signifiers are re-naturalized (re-signed) in discussions of the John/Joan case and want to explore the possible implications of this re-naturalization of gender given that the cultural prescriptions of gender influence each of us, subtly and overtly, on a daily basis. $^{7}$

\section{Re-Signing Gender}

In a celebrated essay, Suzanne Kessler ("Medical") illustrated the "medical construction of gender" by investigating the logic physicians use in making decisions about the case management of intersexed infants (hermaphrodites). ${ }^{8}$ By looking at both the medical research that has proliferated on the topic, and at the practices of physicians (e.g., their "talk" about intersexed children amongst themselves and when advising parents of intersexed children of possible options), Kessler makes a number of observations about the medical construction of gender. First, in line with Judith Butler's observation of the always already discursive body, Kessler notes that physicians make decisions about which gender the child should be assigned based on (heteronormative) cultural factors, even though they claim a biological basis for gender in the decision making process. That is, while physicians might note in 
conversation and in their research that biological factors (e.g., chromosome makeup) should be the major factor in the determination of gender assignment, "biological factors are often preempted in their deliberations by such cultural factors as the 'correct' length of the penis and capacity of the vagina" (3). In making decisions on whether to surgically reassign the intersexed child as male or female, physicians make the primary determinant of their decision the child's ability to fit in socially with whatever body can be constructed. More, while an intersexed body is arguably a "natural body" in that it developed without intervention, doctors construct gender rather than discover it in the case of hermaphrodites by making decisions on what "bad" genitals need to be removed and what "good" genitals need to be repaired or made "normal." Hence, Kessler argues, doctors conceive of male and female as natural gender categories and attempt to create male or female bodies out of ambiguous genitalia. ${ }^{9}$ As Kessler notes, "language and imagery help create and maintain a specific view of what is natural about the two genders, and, I would argue, about the very idea of gender-that it consists of two exclusive types: female and male" $(25) \cdot{ }^{10}$

While I intend to draw on Kessler's insights, the case of John/Joan provides a different arena for the study of gender, both because of its public nature and because it involved a child who was born with unambiguous genitalia. That is, by investigating both medical and public discussions of the John/Joan case-and by paying attention to what evidence from the medical literature is crystallized in mass mediated discourses, we are provided with a view of broad cultural articulations of gender signifiers and gender behaviors. Again, as the case unfolds, the gender specific constraints on behavior are parallel, regardless of whether the descriptions are coming from a constructionist or essentialist position. More, the behaviors are said to be visible as markers "on" the body (e.g., clothing, hair styles) and as markers that reveal impulses "in" the body (e.g., body orientations, personality traits)." While the arguments I look at below posit the behaviors in either primarily constructionist or primarily essentialist terms, we may ultimately see these markers, gestures, and acts, as Butler reminds us, as "performative in the sense that the essence or identity that they otherwise purport to express are fabrications manufactured and sustained through corporeal signs and other discursive means" (Gender 136). Further, to see these markers, gestures, and acts as performative exposes a politics that is occluded by the constructionist and essentialist positions taken up around the case.

The representation of the case as an example of gender constructionism begins when John Money, the physician who carried out John/Joan's reassignment and observed the case for years, writes about the case or is quoted by others in its early stages in the mid to late 1960 s. $^{12}$ On the other hand, Milton Diamond and Keith Sigmundson (and others who take up their position in the 1990s) represent the "natural" position by suggesting that "the brain" or body determines gender and that individuals have impulses as male or female that outweigh social upbringing. ${ }^{13}$ Whether John/Joan is viewed as being successfully reassigned as female or as having struggled against the reassignment, however, what Money sees as the signifiers of what it means to act male or female are identical to what Diamond and Sigmundson see as the signs of male or female-ness. Hence, when their discussions are made public, the signifiers of dominant gender performance are again reified and natural- 
ized as signs of the body's gender/sex. Whether constructed or essential, the markers of gender behavior are reified on binary grounds; identical iterations of gender behavior are stabilized.

In Money's early comments on the case in Man and Woman, Boy and Girl, he notes that John/Joan's parents implemented the change of sexual assignment of the child initially (pre-surgery) with a change of name, clothing and hairstyle. Relying on letters of success as reported by the child's mother, Money notes that the effects of these changes helped feminize the child. For Money, signs of the reassignment's success could be found in the child's "clear preference for dresses over slacks" and her pride "in her long hair" (119). Money quotes John/Joan's mother reporting that Joan "just loves to have her hair set; she could sit under the drier all day long to have her hair set" (120). Significantly, when Time initially reports on the case, the anonymous author employs the quotations concerning John/Joan's love of having her hair set and her predilection for "frilly" clothes as the primary and convincingevidence that the child had successfully become a girl ("Biological" 34). ${ }^{14}$ As time passes and Money provides updates about the case in trade books such as Sexual Signatures, he continues to emphasize the child's interest in feminine clothing and hair as a powerful sign of the success of the gender change. When John/Joan reached age 5, Money notes that the child successfully preferred "dresses to pants, enjoyed wearing her hair ribbons, bracelets and frilly blouses, and loved being her daddy's little sweetheart" (97). In short, taking constructivist positions on gender, Money and those who write about the case from Money's position use the child's successful use of common gender signifiers as evidence that gender is purely a matter of how one is socialized (in short, "because John/Joan likes dresses, she acts/is female").

On the other hand, when the case is reported as a failure in 1997, Diamond and Sigmundson employ these same signifiers as signs, as evidence that the reassignment had in fact always been a failure, that John/Joan rejected "feminine" clothing and hair styles because "she" had in fact always been a male. In Diamond and Sigmundson's report, John/Joan's mother is quoted observing that, for multiple reasons, including her desire that the reassignment be successful, she did not provide Money with the truth about John/Joan's behavior. What is significant here is not that Diamond and Sigmundson get closer to "the truth" of John/Joan's behavior as a child but instead that the gender signifiers used in their reports of the case's failure are the same ones employed by Money in his descriptions of the case's success. For example, John/Joan's mother notes in Diamond and Sigmundson's essay that she "put this beautiful little dress on him [...] and he immediately tried to rip it off; I think he knew it was a dress and that it was for girls and he wasn't a girl" (300). She also notes that John/Joan showed more desire to shave with her father than to use makeup or set hair with her mother (300). In mass mediated articles that draw upon Diamond and Sigmundson's report, this evidence is crystallized as illustrating the case's failure, as if these gender signifiers are linked naturally with sex. In effect, this position reverses Money's causal link to argue, "She doesn't like dresses because she is male." For example, the New York Times reports that John/Joan's "new identity never took. Joan would tear off her dresses, reject dolls and seek out male friends. Her mother would try to get Joan to imitate her makeup ritual; instead, she mimicked her father shaving" (Angier A12). The shaving story is repeated in articles in Maclean's, the Los Angeles Times (Roan) and Time (which also repeats the clothing 
story) (Gorman 83). The Rolling Stone essay, the lengthiest and most substantial retelling of the John/Joan case (and one supportive of Diamond and Sigmundson's position), goes into great detail on many of these signifiers of gender. For example, the reassigned adult male "John" is described by author John Colapinto as "a wiry young man dressed in a jean jacket and scuffed work boots" (56). Further, John/ Joan's brother, Kevin, retells the story of Joan's desire to shave, and his mother recounts Joan's attempt to tear off the dress. In general, the family notes that John/Joan never revealed any desire to wear makeup and shared little concern with hair care (64-5). Rolling Stone essayist John Colapinto consistently emphasizes that John/Joan was never comfortable with her feminine hair style, her clothing, or feminine toys. Indeed, the article includes an enlarged quotation in which John/ Joan's mother notes, “'It was a pretty, lacy little dress,' Linda says. 'Joan was ripping at it, trying to tear it off. I thought, 'Oh my God, she knows she's a boy' " (p. 64). Later, when John/Joan is reported to have decided to live according to his/her own desires, Colapinto reports that Joan began not only wearing a jean jacket and work boots, but "her hair was unwashed, uncombed, and matted" (Colapinto 73). More, after meeting and interviewing the reassigned male John/Joan in a Hard Rock Café, author John Colapinto translates John's physical behavior as unequivocal evidence of John's "natural" sex: "The strongest impression I was left with [...] was of John's intense, unequivocal masculinity. His gestures, walk, attitudes, tastes, vocabularynone of them betrayed the least hint that he had been raised as a girl" (Colapinto 95).

Again, I am not suggesting that there is no significance to John/Joan's preferences of clothing or hairstyle. Rather, what is significant is that the authors who see the case as a success and the ones who see it as a failure do not provide two different interpretations of the same event but instead two different actions surrounding the same specific set of signifiers. The assumption for Money is that the appropriate enactment of these signifiers is evidence of successful gender reassignment while for those taking up the biological (sex) position, John/Joan's rejection of these signifiers is a sign of the natural link between sex and gender. The articulation between signifiers and gender performance is so tightly bound, so "naturalized," that John/ Joan's rejection or embracing of "girlish" hair and clothing is evidence of her rejection or embracing of a gender identity. Both Money and Diamond and Sigmundson, articulating the constructionist and essentialist positions on gender, "read gestures as expression of 'authentic' selves, performances as identities" (Phelan 3). In either case, the signifiers themselves are reified. Further, these signifiers are important not only to the researchers involved in the case, but, perhaps more significantly, they are repeatedly employed in mass mediated reports of the case, illustrating their continuing significance in the public's understanding of gender performance and the overall contours of gender culture.

Next, John/Joan's masculine or feminine behaviors are judged on the basis of a number of issues dealing with bodily containment or excess (orientation), with the tendency toward containment (e.g., neatness, gentleness, seated urination) associated with feminity and tendencies toward excessiveness (e.g., loudness, rough and tumble play, standing urination) associated with masculinity. While my earlier discussion dealt with signifiers (or, signs, as the case may be) "on" the body, this section deals with signifiers "in" the body (e.g., impulses). In Money's earliest "popular" report on the case (Money and Ehrhardt), he makes a number of 
observations about containment of the body, many of which are highlighted in the Time article that extracted portions of the report ("Biological"). Money notes: "Related to being dressed nicely is the sense of neatness. The mother stated that her daughter by four and a half years of age was much neater than her brother [.. .] 'She likes for me to wipe her face. She doesn't like to be dirty, and yet my son is quite different.' 'I've never seen a little girl so neat and tidy as she can be when she wants to be'" (Money and Ehrhardt 119). Further, John/Joan is said to enjoy helping the mother keep the house and kitchen clean while the twin brother has no interest in the same activities (Money and Ehrhardt 121, "Biological"). Three years later, in Sexual Signatures, Money notes that while John/Joan is an aggressive child, her aggressiveness is expressed "in fussing over her brother [...] like a mother hen" (Money and Tucker 97). She is described as "neat and dainty," often attempting "to help in the kitchen" (Money and Tucker 97).

The issue of neatness and containment carries over to the restroom where, as Money reports, while John/Joan had tried "standing up" to urinate at age two, "as many girls do," she learned to successfully urinate sitting down after discovering that when she tried copying her brother's urination style, she made "an awful mess" (Money and Ehrhardt 120). As I will illustrate, the issue of how John/Joan urinates/ desired to urinate becomes more significant in the 1997 retelling of her life story. In this way, the case illustrates Marjorie Garber's employment (13-7) of Lacan's notion of "urinary segregation." Accordingly, despite all other differences men and women may have with other men and women, the act of urination, as symbolized by restroom doors, acts culturally as an imperative tie between all men and between all women (Garber 13-7).

While such claims for gender might not be surprising given the early and mid 1970 s dates of some of these publications (although I actually would have assumed that their stereotypicality would be a bit out of step even for the 1970 s), the same signifiers are employed in articles pointing to the failure of the John/Joan reassignment. For example, Milton Diamond summarized a BBC documentary that focused on the case and noted that, from what the reporters had been able to discover about John/Joan, the reassignment had been a failure; the girl (John/Joan) was living unhappily and showed signs of being masculine. In the documentary, one of the psychiatrists familiar with the case noted the masculine way John/Joan moved: "The child $[. .$.$] has a very masculine gait, er, looks quite masculine" (Diamond "Sexual$ Identity, Monozygotic" 183). In Diamond and Sigmundson's later report on the failure of the case, they made a number of observations about John/Joan's early life, many of which again focused on the lack of bodily containment John/Joan showed as a child. The two noted that "Joan did not shun rough and tumble sports" (300). More, they quote her mother observing that, while John/Joan may have looked like a girl, "When he started moving or talking, that gave him away, and the awkwardness and incongruities become apparent" (301). In articles in Time and the Los Angeles Times, we find repeated the evidence that John/Joan was clearly masculine because she enjoyed the rough and tumble play involved in climbing trees (Gorman 83, see also Roan E8; Diamond "Sexual Identity and Sexual"). In the Rolling Stone essay on the case, John/Joan's brother, Kevin, observes: "When I say there was nothing feminine about Joan, I mean there was nothing feminine. She walked like a boy. She talked about guy things, didn't give a crap about cleaning home, getting married, 
wearing make up. We both wanted to play with guys, build forts, and have snowball fights and play army" (Colapinto 64-5).

Further, the issue of urination again is employed here (and in almost all of the mass media reports concerning the case) as an important sign of John/Joan's gender and its natural link to sex. Diamond and Sigmundson note that John/Joan began urinating standing up, despite the fact that others didn't want her to: "At school, at age 14 years, she was caught standing to urinate in the girls' bathroom so often that the other girls refused to allow her entrance" (300). As John Colapinto quotes the adult male John/Joan: "It was no big deal; it was easier for me to do that. Just stand up and go" (73). The same evidence is raised in the New York Times (Angier A18), Time (Gorman 83), and the Los Angeles Times (Roan E1).

Again, then, just as with the child's clothing and hair style, a single set of signifiers (the gait, the gestures, body movements, rough and tumble play, and the stance for urination) are used to illustrate masculinity and femininity in binaristic fashion, regardless of whether gender is posited as a product of socialization or of the materiality of the body (its sex). In terms of gender culture, we clearly see in the argument over John/Joan's body the signifiers that are employed in the judgments people make of each other and of themselves in their evaluations of gender performance.

\section{Gender and Assumed Heterosexuality}

Paralleling Judith Butler, Elspeth Probyn notes that "Personhood is always gendered" (2). One of the reminders that the John/Joan case brings to the fore is that, as we are gendered (or "sexed" to use Probyn's term), so are we simultaneously situated in relation to a "compulsory heterosexuality" (Rich). ${ }^{15}$ In clearer terms, perhaps, Butler notes that "the institution of a compulsory and naturalized heterosexuality requires and regulates gender as a binary relation in which the masculine term is differentiated from a feminine term, and this differentiation is accomplished through the practices of heterosexual desire" (Gender 22-3). In this case, both predicted and performed heterosexual desire (and the rejection of homosexual desire) operate rhetorically as evidence of John/Joan's "real" gender. For Money and the reports that articulate his position, Joan is "truly" a girl when she desires boys as partners; for those holding sex as essential, John is proven "truly" to be a male when he aggressively pursues heterosexual relations with women.

Despite the fact that both Money and Diamond argue that sexual desire is somewhat autonomous from "sex" (e.g., neither suggests that males absolutely must be attracted to females and vice-versa), both of them actively utilize evidence of heterosexuality in this case as strong evidence of John's/Joan's proper gender behavior. More, as I illustrate below, the nature of John/Joan's heterosexual desire is drawn up in aggressive terms and becomes some of the most often repeated evidence in scientific reports about the case. Indeed, from the time that John/Joan was first reassigned as female until his chosen reassignment as male, the question of sexuality and its significance within the debate over gender's constructedness/ naturalness is raised. In short, similar to the discussions of the physical signifiers of gender, what John/Joan does (or will do) with his/her body sexually is utilized rhetorically as evidence for the success or failure of the reassignment.

When Money first writes about the case in 1972 in Man and Woman, Boy and Girl 
(Money and Ehrhardt), he assumes the importance of heterosexuality and future motherhood for the child's proper gender behavior when he notes the importance of informing John/Joan early on that while she could not have children naturally, "she would become a mother by adoption, one day, when she married and wanted to have a family" (119, emphasis mine). When the child's mother goes on to note in this same work that she had explained to the twin brother that he would someday become a daddy "and grow muscles so he could take care of mommy and baby, and go to work in a car like daddy does [...] I've explained to each what their function will be as a grown-up, [...]" (120), Money follows by noting that the mother consistently gave the twins good examples of the "wife" and "husband" roles (121). Similarly, Money notes with approval that the twin son would sometimes smack John/Joan on the fanny as a sign of affection (121), illustrating that each was learning their proper gender behavior. Further, in an interesting twist in which Money assumes that John/Joan will become interested in a male sex partner, he notes that cases like this one "represent what is, to all intents and purposes, experimentally planned and iatrogenically induced homosexuality. [...] Postsurgically, it is no longer homosexuality on the criterion of the external sex organs nor of the sex of replacement hormonal puberty" (235). The assumption Money is making here is that, given a female body and raised as a girl, John/Joan would naturally choose a male partner.

This same theme continues in Money's popular and scientific reports and is crystallized in mass mediated accounts of the case. Further, Money and mass mediated reports on John/Joan's heterosexuality also point to other cases to reify the articulation of heterosexual desire and proper gender behavior. For example, the Time magazine report on the case quotes Money making note of a case of two hermaphrodites who were reassigned, one as male and one as female: "The girl therefore reached preadolescence expecting to marry a man; in fact, she already has a steady boyfriend. The boy by contrast has a girl friend and 'fitted easily into the stereotype of the male role in marriage' even though 'he and his partner would both have two X-chromosomes'" ("Biological" 34). In an account of the case in 1975, Money notes that the decision about John/Joan's reassignment as a girl had to be made early enough in the child's life so that her "erotic interest would almost certainly direct itself toward the opposite sex later on" (Money and Tucker 94). In each example, the assumption is that a successful gender reassignment would be signified in part by heterosexual desire, and in persistently reiterating this link, its disciplinary strength is maintained.

When the case is discussed in 1997, and we learn that John/Joan chose to be reassigned as male, heterosexual prowess is again emphasized; this time, however, they focus on his desire for, and attractiveness to, women. Similar to the arguments made by, and in support of, Money's position, heterosexuality is again used as evidence of proper gender behavior despite the fact that Diamond's position does not necessarily entail it. In its most basic form, Milton Diamond's position on gender identity is that the hormones accompanying a child's gender, both while the child is in the womb and after birth, create gender identity such that one cannot simply reassign a child after birth (for Diamond, this is the case with both hermaphrodites and those cases like John/Joan in which the reassignment came as the result of an accident). While Diamond is clear at times that he sees sexual preference as 
somewhat autonomous from gender (see, e.g., Diamond "Sexual Identity and Sexual Orientation" 207), he also persistently provides examples of cases which imply compulsory heterosexuality (e.g., cases of males with ambiguous genitalia who were raised as females, but develop male genitalia and sexual desires for females as they go through puberty). Diamond's assumption is a reiteration of what Alice Dreger notes is the historical position of those who study cases of "doubtful sex" (hermaphroditism). As she observes, at the turn of this century, it was an unstated assumption that a body's natural sex would reveal itself through heterosexual desire: "The assumption that true males-even those with mistaken identitywould naturally desire females, and true females males, pervaded the medical literature on doubtful sex" (88). Indeed, in the case of John/Joan, Diamond and mass mediated reports sympathetic to his position persistently crystallize John/Joan as aggressively heterosexual.

In Diamond and Sigmundson's report on the case, they provide a heterosexual theme that is the most repeated piece of evidence in the case as it unfolds in mass mediated reports. The two note that after John/Joan chose to be reassigned as male at age 15, he began to make other changes: "At 16 years, to attract girls, John obtained a windowless van with a bed and bar. Girls, who as a group had been teasing Joan, now began to have a crush on John" (300). This signifier of the use of a van-a windowless van with a bar and a bed-to pursue heterosexual activities so clearly resonates with popular cultural notions of gender and sexuality that it appears repeatedly in articles about the case. It is as if, in bed, hidden by the lack of windows, John's "true" sexual desire would express itself. For example, in a New York Times report that extends the aggressiveness of his heterosexual desire, the author notes that after Joan became John, "He got himself a van with a bar in it. Dr. Diamond said in an interview, 'He wanted to lasso some ladies' " (Angier A12). The article goes on to discuss John/Joan's marriage to a woman and adoption of her children, emphasizing John/Joan's ability to have intercourse and orgasm with his newly constructed penis (A12). Similarly, during an interview on ABC's PrimeTime Live, the adult John is asked if he is able to have normal sexual relations with his wife using his reconstructed penis-a question which should be irrelevant to John's "true" gender ("Boy"). US News and World Report's John Leo similarly reports that after his surgery, "At age 16, he bought a van with a bed and bar and started to pursue girls. At 25, he married a woman with three children [. . .]" (p. 17).

Finally, John Colapinto's Rolling Stone essay, in addition to recounting the same stories about John/Joan's coming out as a heterosexual, reports that, despite the fact that Money talked about John/Joan as heterosexual in his published reports about the case, he had already asked John/Joan's parents if they would have trouble raising a lesbian (Colapinto 70). In this way, Colapinto implies that John/Joan had always been attracted to women sexually and hence, using a heterosexual logic, had always been male. Just as Money employs John/Joan's heterosexuality as a sign of the success of the child's reassignment, Colapinto's essay employs "John's" heterosexuality (and "Joan's" potential homosexuality) as evidence of its failure. In both cases, heterosexuality is signified-indeed emphasized-as a norm in the performance of gender (or, from the biological position, as an expression of the body's sex). One can safely assume given the hetero-normativity of popular media culture that if John/ Joan had become a homosexual male after his reassignment to male, the case would 
not be quite as clearly used as evidence of gender's biological determinism in that his performance of masculinity would not have been heterosexual masculinity. The disciplinary power of normative heterosexuality is powerful indeed.

\section{Re-naturalizing Gender: The Brain as Sex Organ}

It has become something of a commonplace to note that "the brain is the most important sexual organ" as a way to suggest that one's beauty, one's ultimate sexual attraction, lies more in how one holds oneself, how interesting one is "as a mind," than in the superficialities of the body. In the case of John/Joan, this same phrase is repeatedly invoked, albeit to different ends. In the 1997 reports about the case, the resignifying of the brain as the very basis for gender and gender impulses implies that gender is natural (i.e., gender is sexed)-a product of the development of brain, body, and identity as the result of hormones and chromosomes. As Marjorie Garber notes of this type of argument, gender essentialism is alive and well in scientific and popular culture; it has simply moved from being "on" the body to being "in" the body (e.g., chromosomal) (108). Indeed, despite the fact that Diamond (and Sigmundson) posit gender as determined by both nature (the body, the brain, hormones) and nurture (cultural pressures, influence), ${ }^{16}$ the case is reported repeatedly as if it provides evidence for a complete reversal of any argument for social pressures on the shaping of gender and gender performance. Much as will be seen in the articulation of feminism below, the case becomes one in which a totalizing of positions in mass media outlets turns this case into one in which the "brain" (its sex) is the sole determinant of gender.

In William Reiner's article accompanying Diamond and Sigmundson's update on the John/Joan case, he notes that "the organ that appears to be critical to psychosexual development and adaptation is not the external genital but the brain. If the brain knows its gender independent of social-environmental influences, then we need to be able to predict what that gender is" (225). While neither Reiner, nor Diamond and Sigmundson, are arguing that sexual identity is completely determined or "unpliable," the mass mediated representation of their position transforms their argument into an all or nothing proposition in which "nurture" is displaced. For example, the New York Times article on the case is titled "Sexual Identity Not Pliable After All, Report Says" (Angier), noting that the follow-up on the John/Joan case "suggests the opposite" of Money's theory: "A sense of being male or female is innate, immune to the interventions of doctors, therapists and parents" (Angier X). In such wording, gender is entirely innate, "the opposite" of Money's theory. Similarly, Maclean's notes that "despite everyone telling him constantly that he was a girl, [...] his brain knew he was a male" ("Rethinking" 31). Time notes that the follow-up study shows Money's experiment was "a total failure," that gender is determined by the brain (Gorman 83). PrimeTime Live's Nancy Snyderman notes that the lesson of the case is that gender identification "comes from the brain, not the genitals" and suggests that continued belief in the constructedness of gender in the wake of the failure is "bad science" ("Boy"). The Los Angeles Times observes that the case "provides stark evidence that a person's brain predetermines sexual identitynot one's anatomy or social environment" (Roan E1). Finally, the Rolling Stone essay, titled "The True Story of John/Joan," argues that the "case was a failure, the truth never reported" "the most important sex organ is not the genitals; it's the brain" (97). 
Such comments assume that scientific study works on the basis of using singular cases to prove particular theories and disprove others, rather than as offering support for particular cases or the falsification of others. In this way, these publications produce a gender theory through a reading of one particular study, a study that is said to prove that gender is not pliable, that the brain is the sex organ that determines gender.

The argument that the brain is the primary sex organ also implies an interesting moral equation. Toward the conclusion of the Rolling Stone analysis of the case, John/Joan makes the following observation about what his life has taught him about being a man:

'From what I've been taught by my father,' John says, 'What makes you a man is: you treat your wife well, you put a roof over your family's head. You're a good father. Things like that add up much more to being a man than just bang bang bang-sex. I guess John Money would consider my children's biological fathers to be real men. But they didn't stick around to raise the children. I did. That, to me, is a man' (Colapinto 97).

While I have no desire to put committed fatherhood in a negative light, what is interesting about this comment, in combination with the way in which gender is constructed throughout the discourse of the case, is the link made between the naturalization of gender behaviors and the moralizing of these behaviors. In effect, gender behaviors, from the activities one performs to the clothes one wears to the way one urinates, are configured here as being determined by the brain. Hence, our impulses to act in particular ways are posited as totally determined in this discoursemen take wives, have children, and then provide homes for them. However, given our obvious ability to ignore our impulses/duties as men or women (i.e., not every "man" takes a wife or has children as John seems to indicate above; not every woman needs a roof put over her head by the man), our inability to enact these roles gets recast as an unwillingness to perform gender correctly (including physical activities and erotic interests), an unwillingness that is seemingly posited as immoral. In the discourse of this case, gender impulses are constructed as determinate, and our willingness to work with or against them a matter of morality (i.e., being a "man" means being a good father rather than not having children, rather than being homosexual). Given the interconnections, in this case, of what gender means in terms of our life activities, our sexual desires, and our daily politics, John/Joan constructs a situation in which the more closely one follows traditional gender politics, the closer one is to behaving morally. Hence, discourses like those in this case that link gender behavior "scientifically" to a supposed sex work to reify the "prohibitions and taboo[s]" (Butler Bodies 95) that act to discipline and mark gender performances; a discourse that constructs gender behavior as scientifically illustrated to be natural, turns "good" or "bad" performances according to patriarchal rules into moral or immoral behaviors, and strengthens the ritualized iterations of proper gender behavior.

\section{John/Joan and the Articulation of Feminism}

While the John/Joan case clearly calls for a critical reading of the way the discourse surrounding it continues to reify gender binarism and hetero-normativity, an ancillary but related articulation in this case concerns public representations of 
feminism and the way in which it is rhetorically linked to the case in theory and in deed. From the first popular culture reporting of the John/Joan case in Time ("Biological"), discursive links were made between the assumptions of the case and those of feminism/women's studies. This was certainly in part due to John Money's own alignment of his claims with theories he saw as supportive of "women's liberation." Despite the irony of the fact that Money's discourse ultimately reifies disciplinary gender signs, the case is used early on by Money and others as evidence for many of the claims of feminism (again, feminism here is an uncontested terrain). However, even while such claims are used to support feminism, the effects are complicated because, as I've noted above, (1) the "feminism" or "women's lib" articulated with the John/Joan case is a particular type of feminism that gets totalized as feminism as a whole and (2) once the case is articulated as evidence for feminism, later refutation of the success of the case is also seen as a refutation of feminism as a whole.

In the 1973 article in Time, "Biological Imperatives," the author notes that the case "provides strong support for a major contention of women's liberationists: that conventional patterns of masculine and feminine behavior can be altered" (34). The report notes that, while some scientists might argue that the biological differences between men and women limit the flexibility of sex roles, "Money is convinced that almost all differences are culturally determined and therefore optional" (34). This passage in Time is referred to repeatedly as the case unfolds publicly over the next two decades, illustrating a cultural need to come to grips with the claims of feminism. Milton Diamond, in one of his brief refutations of the case in 1982, notes the Time passage and argues that the John/Joan case in fact requires more scrutiny both because it has been used as the basis on which many other children have had sex reassignments and because the case has been utilized in "numerous elementary psychology and social texts" as well as by Masters and Johnson to assert that "it is basically nurture, not nature, that determines sexual identity as male or female and the attendant gender roles" ("Sexual Identity, Monozygotic" 182). Further, in Diamond and Sigmundson's 1997 article, they again quote the same passage from Time and assert that "Sociology, psychology and women's studies texts were rewritten" to fit Money's argument as were many "lay and social science writings" (300). Hence, Money's arguments and their distillation in Time become the basis on which the case is articulated as providing evidence for "women's studies" as a whole rather than providing evidence for a particular argument about gender.

After Diamond and Sigmundson release their updated findings about the case, bringing on interest about the meaning of "Joan's" reassignment as "John," the link to feminism becomes problematic. Once again, the passage in Time that notes the case's link to women's studies is referred to or quoted directly in 1997 articles in Time (Gorman), Rolling Stone (Colapinto), and US News and World Report (Leo). Further, each of these articles notes that the case has been cited in numerous women's studies texts, and was used, as John Colapinto puts it, to "buttress the feminist claim that the observable differences in the tastes, attitudes and behaviors of men and women are attributable solely to cultural expectations" (66). In an essay that particularly trades on this connection in an extended fashion, John Leo in US News and World Report (who also quotes the same passage from Time) begins by observing the outcome of the case and the fact that "It has been cited over and over in psychological, medical 
and women's studies textbooks as proof that, apart from obvious genital differences, babies are all born as sexual blank slates-male and female attributes are invented and applied by society. Now all those texts will have to be rewritten" (17). However, Leo's argument does not stop at arguing that women's studies must now be rethought, but rather he reinserts feminism at the beginning of the case, making it liable for the very decision for the surgery: "Why was this disastrous experiment undertaken? One reason is that it's easier to construct a vagina than to reconstruct a penis. But another reason is just as obvious: It was a chance to prove a rising academic and feminist theory about gender [...] that almost all sex differences are culturally determined" (17). Leo notes that the John/Joan case allowed the creation of gender studies which saw all differences between men and women as "socially constructed by men to oppress women" (17). After positing feminism as the cause for the surgery and using the case as evidence that feminism is a failed ideology, Leo, borrowing from Daphne Patai, goes on to note that the case won't mean much to "campus feminists" who will "just shrug it off": "The whole point of being an ideologue is that new information doesn't disturb your worldview" (17).

While it is certainly the case that a great many versions of feminism include the idea that gender roles are (at least in part) socially constructed, the argument presented by Leo and others is that feminism has claimed that every aspect of gender is socially constructed. After totalizing "social roles" as feminism itself, he (and others) are then able to employ the "new outcome" of the John/Joan case to suggest that feminism (again totalized) is completely intellectually bankrupt. Rather than taking this as an occasion for revision, it becomes an occasion for dismissal.

As has been pointed out many times before, such arguments make one feminism out of the multiple feminisms. That is, while one might give very broad parameters of feminism to which a number of people could agree, ${ }^{17}$ specific theoretical assumptions concerning the relationship between gender, sex, identity, and behavior are certainly open to a large variety of perspectives within different feminist positions (as well as other psychological and philosophical positions). This case represents one more location where feminism as a concept is concretized in popular culture, where feminism is "performed" by a variety of people, many of whom are not themselves supportive of a feminist position. When one notes the many ways in which feminism is caricatured and dismissed in conversations in the academy and in the public sphere, the need for the careful articulation of any given stance is clear. Indeed, given the tight link built between the case and feminism, cultural critics and feminists could do worse in finding a point of articulation over which to struggle for feminism and to complicate its meanings.

\section{Conclusion}

Investigating the way theories of gender, especially those put forth by John Money, have influenced the way intersexed (hermaphrodite) children are assigned gender by physicians, Suzanne Kessler illustrated that such decisions are often made by doctors more on the basis of cultural signification than on the basis of biological concerns. For example, because of a cultural belief that it would be traumatic for a male to go through life with an unusually small penis, a decision might be made to remove the penis of such an intersexed child and construct a vagina in its place. While such a decision would be made on the basis of multiple cultural factors, the 
issue would be presented to the parents, according to Kessler, as a biological issue. In essence, Kessler is arguing that physicians, faced with the material bodies of hermaphrodites, are influenced to see and interpret these bodies, and the possibilities for such bodies, through the same gender culture lens that is pervasive to varying degrees in the way each of us, in the same historical communicative community, understand gender and its performance.

By investigating the story of John/Joan as it plays itself out on the level of civic mass mediated discourse (and its translation from the medical community to mass culture), we are able to see some of the ways our broad gender culture is constructed and struggled over. More, we are able to see some of the ways our gender culture not only affects the material bodies of intersexed infants but also the ways it affects and influences our interpretation of each other's behaviors and bodies, the way we all, to varying degrees, take part in the reiteration of the norms of gender binarism and normative heterosexuality (e.g., how we monitor the behaviors of others and of ourselves, how we discipline that behavior through force, ostracism, taboo, and the reiteration of normative gender assumptions). If we see gender culture as a "society's understanding of what is possible, proper, and perverse in gender linked behavior, and more specifically, that set of values, mores, and assumptions which establishes which behaviors are to be seen as gender linked" (i.e., if gender culture is seen as the rules for gender performance and the morals of performing them well) (Ramet 2), we see here a case in which the rules for gender performance are laid bare.

As we have seen, the rules for gender performance in this case are not only surprisingly traditional in form but also fairly rigid. Indeed, and this is key, the rules are so rigid that binaristic signifiers of gender are employed even by those who hold theoretical positions that should give no credence to binaristic theories of gender. The rigidity of the gender binarism is central to the arguments of both constructionists and essentialists, especially when it comes to making public account of this specific case. This rigidity can perhaps be accounted for because it arises in the discursive aftermath of a case in which the foundations of gender are radically placed into question, and as Alan Hyde notes, it is during such periods that we most carefully call forth our definitions of the body (11). Not only do the rules of gender culture and gender performance continue to dictate such superficial features as clothing and hair, but they also prescribe the positioning of the body and its desires on male-female grounds. Indeed, the two clearest themes that were repeated in each summary of the case in mass mediated journalism were John/Joan's masculinity as seen in her desire to urinate standing up and John/Joan's masculinity as witnessed by his desire, immediately upon surgical reassignment, to aggressively perform heterosexuality through the purchase of a van with a bed and a bar in order to "lasso some ladies" (Angier A12). To be male or female, then, continues to mean that one performs within a fairly rigid set of constraints. Regardless of the multiple examples one can give of the plasticity of our culture in terms of gender, and regardless of how much behaviors and criticism can work to insist that gender behavior is never determined fully in advance, this case illustrates that, at least when mass culture is troubled about gender, "signs" of proper gender behavior are readily called upon to stabilize cultural fears about gender ambiguity. The disciplinary mechanisms holding gender steady are powerful indeed. Regardless of what version of the John/Joan story one believes, regardless of what John/Joan did or is doing with his current 
body, what matters rhetorically and culturally is the way particular activities and impulses were repeated and reaffirmed in mass media outlets as evidence of gender behavior and misbehavior. ${ }^{18}$ As such, they help provide the contours of our cultural understanding of gender expectations and its links with public morality.

Secondly, one can clearly see in these articles the way feminism is represented in mass culture, and how feminism is constructed by those who attack it. As I have shown, one particular theory-that gender is purely a cultural construct-gets represented as the main thesis of all feminist theory. Given the articulation of the John/Joan case with feminism, criticism of this case is argued to also be an undermining of feminism, even though one would be hard pushed to find purely discursive theories of gender. Moreover, finding fault with the John/Joan case allows one to place feminism at fault for the "crimes" of this experiment. That feminism so easily fits into these public arguments in this fashion speaks again for the need for a complicating of feminism on the public level.

Finally, in Alan Hyde's recent discussion of the way the body is constructed in legal discourse, he notes that his purpose is to encourage "an explosion of competing metaphors" of the body, to make a plea "for the multiplication of bodily performance" $(80,123)$ similar to Gordene MacKenzie's call for the destruction of solid gender concepts and a move to a "transgender nation" (1) and Celeste Condit's recent call for a gender diversity perspective of rhetoric that would emphasize the ongoing construction of gender, observing that identity categories "will necessarily be fragmentary and context-bound" ("In Praise" 97). ${ }^{19}$ Hyde goes so far as to note that this multiplicity of performances is nearly inevitable: "Attempts to figure a pure or inviolable body, pure because or insofar as it is 'natural' and 'immutable', are doomed to fail, are deeply out of touch, with the complicated circuits of will, control, and power that condemn the modern body to constant mutability as to weight, appearance, and muscle tone" (129-30). What this case illustrates, however, is just how strong the constraints against such plasticity, such play, such indeterminacy can be. As Susan Bordo notes both in her Unbearable Weight (245-76) and more recently, in Twilight Zones (107-35), while it may indeed be the case that plastic surgery and other cosmetic options give us the illusion that the body has become far more "plastic," increasing the number of options for the public performance of gender, the same options are consistently chosen and the same body types celebrated. No one chooses reverse liposuction; no one decides to have their teeth darkened. Instead, while individuals do make such choices as increasing their breast size, they do so as a matter of, as Bordo calls it, "free choice under pressure" (Twilight 44). Rather than the concept of the "immutable" body being out of touch with "the complicated circuit of will, control and power," perhaps it is far more in touch with the gender culture we live within than we care to think. At the very least, we must all take greater responsibility for the ways that the performance of gender continues to be tightly constrained, and morally suspect, and we must continue to find ways to complicate those constraints.

\section{Notes}

The author would like to thank Barbara Biesecker, Bonnie Dow, Judith Hamera, Karen Shimakawa, and the anonymous reviewers for their insightful and rigorous comments on earlier drafts of this essay. Thanks, too, to Roy Hargrove for Habana. Earlier versions of this essay were presented at the June 1999 meeting of the International 
Communication Association in San Francisco, CA and the April 1999 meeting of the Southern Communication Studies Association in St. Louis, MO.

"Reassignment" is the term used by medical professionals to signify that a child has been designated as being of a gender different than that announced at birth. For example, if a child with ambiguous genitalia was first announced as male, and a decision is subsequently made to surgically turn the child into a female, the child is said to be reassigned as female.

${ }^{2}$ The case was more readily known as the "Twins" case before its recent updating.

${ }^{3}$ The most interesting and full mass media presentation of the case is an article in Rolling Stone by John Colapinto, and the fullest account in the scientific community is the article which "broke" the case by Milton Diamond and H. Keith Sigmundson.

${ }^{4} \mathrm{I}$ want to be clear that I am using this case, and the discourse that surrounds it, to understand the meaning of gender in contemporary culture. I am not using it to understand what it means to be "gender ambiguous" as an experience. I would recommend that anyone writing in the area of gender ambiguity or cases of transgender performance see Jacob Hale's "Suggested Rules for Non-Transsexuals Writing about Transsexuals, Transsexuality, Transsexualism, or Trans _." These can be found at http://www.actlab.utexas.edu/ sandy/hale.rules.html."

${ }^{5}$ I searched the case by using a variety of data bases, including the Reader's Guide to Periodical Literature, the University of California's Melvyl system, and Vanderbilt University's Television News Archives.

${ }^{6} \mathrm{I}$ should be clear that there is nothing as subtle as a Butlerian deconstruction of the gender-sex division going on in public discussions of the case. It is an argument between these two positions. What $I$ am attempting to do is to suggest that the argument about the case illustrates the way in which a specific type of gender perfonnance is reified in this case by all those making public arguments.

"In rhetorical studies circles, my method here amounts to "critical rhetoric," as outlined by Raymie McKerrow and refined by $\mathrm{McGee}$, and Ono and Sloop. I am concentrating on pulling together fragments of popular discussions of the case-(dominant) discourses rather than marginal ones. As such, I realize that I am only drawing certain types of fragments while not looking necessarily into their use by individuals or within vernacular conversations about the case. Further, I should be clear that this essay is not about the "real person" John/Joan-it is about dominant cultural representations of that person and the ways that these representations are part of our dominant cultural understandings of gender. Further, I am nol denying that people can transgressively perform gender "against the grain" or read this case "against the grain." In a sense, this essay is about the constraints we all face in trying to act transgressively.

"The essay, "The Medical Construction of Gender," is now reprinted as a chapter of Kessler's book, Lessons from ithe Intersexed. A very good recent history of medical discussions of hermaphroditism is Alice Domurat Dreger's Hermaphrodites and the Medical Construction of Sex. For other discussions of the gender ideology of science in terms of medical discussions of male and female bodies, see both Emily Martin and Bonnie Spannier's essays on the medical construction of gender.

${ }^{9}$ In her fascinating new history of hermaphroditism, Alice Dreger makes a similar observation and notes that modern medicine, "even when it involves psychosocial theory-in fact remains deeply materialist, reductionist, and determinist in its practical approach to the world, and presumes that a 'successful' female gender requires (and is almost guaranteed by) a certain 'female' sex anatomy, and that a 'successful' male gender requires (and is almost required by) a certain 'male' sex anatomy" (I85).

${ }^{10}$ There is a point that Kessler raises in a footnote of her own that, while also beyond the scope of this essay, should be reinforced and studied elsewhere. Kessler notes in her footnote 9 that "almost all of the published literature on intersexed infant case management has been written or cowritten by one researcher, John Money," and, she notes, "There are no renegade voices either from within the medical establishment or, thus far, from outside" (7). The case of John/Joan, as reported in the essay that finally offered a strong challenge to Money's case (Milton and Diamond) and the Rolling Stone article concerning the case, both make it clear that not only were other physicians hesitant to challenge someone established in the area, but that, as a result, Money was able to report only that evidence that supported his thesis, ignoring evidence that did not support his case. Regardless of where one stands on the question of gender fluidity and performance, this case illustrates that, like the humanities, science has a powerful rhetoric and politics that is often outside the rigor that it normally claims. While not a "hoax" like the infamous Sokol affair, cases like this one, in which reputation makes it impossible to challenge a thesis, are perhaps more dangerous in that people were rhetorically and politically frightened to challenge a theory that continues to shape decisions about cutting into people's bodies and radically altering their lives. Indeed, H. Keith Sigmundson, one of the co-authors of the follow up report on the case of John/Joan that led to the media discussions, claims to have not published an article on the case years before, even though he knew the twins case had not been successful because "I was shit-scared of John Money. He was the big guy. The guru. I didn't know what it would do to my career" (Colapinto 92).

"For some interesting and indeed frightening cases of how tightly thought out gender behaviors and appearances can be for children, especially as revealed in medical discourse, one should see the case studies in Phyllis Burke's Gender Shock.

${ }^{12}$ Money's case is made in a number of places. I will draw primarily on articles written for the lay audience. See Money "Sex," Money and Ehrhardt, Money and Tucker, Money "Ablatio."

${ }^{13}$ Diamond's case is made in a number of places. I would recommend Diamond "A Critical," Diamond "Sexual 
Identity and Sex Roles," Diamond "Sexual Identity, Monozygotic," Diamond and Sigmundson, Diamond "Sexual Identity and Sexual Orientation."

${ }^{14}$ It seems to me that the evidence taken from scientific reports and reprinted in mass media publications is of significant importance in that, because the mass media articles are shorter and written for a lay audience, the evidence chosen is evidence deemed to be convincing to that mass audience.

${ }^{15}$ Kessler (Lessons, 106), drawing on unpublished work by Fausto-Sterling, argues that gender reassignments are made and evaluated on the basis of successful heterosexual performance.

${ }^{16}$ I should be clear here that while Diamond and Sigmundson see elements of gender being shaped by "nurture," I would classify them as "essentialist" in that Diamond's oeuvre has focused on looking at the ways the body's sex behaves despite cultural forces.

${ }^{17}$ For example, in her analysis of the representation of "feminism" on prime time television shows, Bonnie Dow defines feminism broadly as "a set of political ideas and practices-developed through feminist movements, dedicated to the progress of women and the transformation of patriarchy" (xxiii).

${ }^{18}$ To clarify, while those who study John/Joan and those who know John/Joan would obviously find his actions/desires to be important, what he "actually" does is not important in terms of how the discourse about the case represents and reifies cultural understandings of gender and gender behavior. That is, this essay is about John/Joan as a discursive re-presentation and not about the actual person.

19. One might also be tempted to employ Anne Fausto-Sterling's ("Five," "How") call for recognition of at least five sex categories. However, while similar, the Fausto-Sterling argument does not work in quite the same fashion. As Kessler (90) notes, "The limitation with Fausto-Sterling's proposal is that legitimizing other sets of genitals still gives genitals primary signifying status and ignores the fact that in the everyday world gender attributions are made without access to gender inspection. There is no sex, only gender [...]" One interesting way to think through the possibility of multiplicities of "humans" on all levels of identificatory discourse, and one that I heartily endorse, is to Celeste Condit's move ("Post" 355) to understand human beings as "diverse bodies that learn many languages."

\section{Works Cited}

Angier, Natalie. "Sexual Identity Not Pliable After All, Report Says." New York Times, 14 March 1997. A1, A8.

Berlant, Lauren. The Queen of America Goes to Washington City: Essays on Sex and Citizenship. Durham, NC: Duke UP, 1997.

"Biological Imperatives." Time, 8 Jan. 1973. 34.

Bordo, Susan. Tzilight Zones: The Hidden Life of Cultural Images from Plato to OJ. Berkeley: U of California P, 1997.

Bordo, Susan. Unbearable Weight: Feminism, Western Culture, and the Body. Berkeley: U of California P, 1993.

"Boy or Girl?" PrimeTime Live. ABC News. 22 July 1998. Transcripts by Federal Document Clearing House, Inc.

Burke, Phyllis. Gender Shock: Exploding the Myths of Male and Female. New York: Anchor, 1996.

Butler, Judith. Bodies that Matter: On the Discursive Limits of 'Sex'. New York: Routledge, 1993.

Butler, Judith. Gender Trouble: Feminism and the Subversion of Identity. New York: Routledge, 1990.

Colapinto, John. "The True Story of John/Joan." Rolling Stone, 11 Dec. 1997. 55-73, 92-7.

Condit, Celeste M. "In Praise of Eloquent Diversity: Gender and Rhetoric as Public Persuasion." Women's Studies in Communication. 20 (1997): 91-116.

Condit, Celeste Michelle. "Post-Burke: Transcending the Sub-stance of Dramatism." Quarterly Journal of Speech. 78 (1992): 349-55.

Diamond, Milton. "Sexual Identity, Monozygotic Twins Reared in Discordant Sex Roles and a BBC Follow-Up." Archives of Sexual Behavior. 11 (1982): 181-86.

Diamond, Milton. "Sexual Identity and Sex Roles." The Humanist, March/April 1978. 16-9. 
Diamond, Milton. "Sexual Identity and Sexual Orientation in Children with Traumatized or Ambiguous Genitalia." Journal of Sex Research, 34 (1997): 199-211.

Diamond, Milton and Keith Sigmundson. "Sex Reassignment at Birth: Long-term Review and Clinical Implications." Archives of Pediatric and Adolescent Medicine, 151 (1997): 298-304.

Dow, Bonnie J. Prime-Time Feminism: Television, Media Culture, and the Women's Movement Since 1970. Philadelphia: U of Pennsylvania P, 1996.

Dreger, Alice Domurat. Hermaphrodites and the Medical Invention of Sex. Cambridge: Harvard UP, 1998.

Ebert, Teresa L. Ludic Feminism and After: Postmodernism, Desire, and Labor in Late Capitalism. Ann Arbor: U of Michigan P, 1996.

Fausto-Sterling, Anne. "The Five Sexes." The Sciences (March/April 1993): 20-4.

Fausto-Sterling, Anne. "How Many Sexes are There?" New York Times, 12 March 1993.

Garber, Marjorie. Vested Interests: Cross-Dressing and Cultural Anxiety. Routledge: New York, 1992.

Gorman, Christine. “A Boy Without a Penis.” Time, 24 March 1997. 83.

Greene, Ronald Walter. "Another Materialist Rhetoric." Critical Studies in Mass Communication 15 (1998): 21-40.

Hale, Jacob. "Suggested Rules for Non-Transsexuals Writing About Transsexuals, Transsexuality, or Trans_." http://www.actlab.utexas.edu/ sandy/hale.rules.html.rules.html

Hyde, Alan. Bodies of Law. Princeton, NJ: Princeton University Press, 1997.

Kessler, Suzanne J. Lessons from the Intersexed. New Brunswick, NJ: Rutgers UP, 1998.

Kessler, Suzanne J. "The Medical Construction of Gender: Case Management of Intersexed Infants." Signs: Journal of Women in Culture and Society 16 (1990): 3-26.

Laqueur, Thomas. Making Sex: Body and Gender from the Greeks to Freud. Cambridge: Harvard UP, 1990.

Leo, John. “Boy, Girl, Boy Again.” US Neres and World Report, 31 March 1997. 17.

MacKenzie, Gordene Olga. Tranggender Nation. Bowling Green, OH: Bowling Green State University Popular P, 1994.

Martin, Emily. "The Egg and the Sperm: How Science Has Constructed a Romance Based on Stereotypical Male-Female Roles." Signs: Journal of Women in Culture and Society 16 (1991): 485-501.

McGee, Michael Calvin. "Text, Context, and the Fragmentation of Contemporary Culture." Western. Journal of Speech Communication (1990): 274-89.

McKerrow, Raymie E. "Critical Rhetoric: Theory and Praxis." Communication Monographs 56 (1989): $91-111$.

Money, John. "Ablatio Penis: Normal Male Infant Sex-Reassigned as a Girl." Archives of Sexual Behavior 4 (1975): 65-71.

Money, John. "Sex Reassignment as Related to Hermaphroditism and Transsexuality." Transsexualism and Sex Reassignment. Ed. Richard Green and John Money. Baltimore: John Hopkins UP, 1969. 91-114.

Money, John and Anke A. Ehrhardt. Man and Woman, Boy and Girl. Baltimore: John Hopkins UP, 1972.

Money, John and Patricia Tucker. Sexual Signatures: On Being a Man or a Woman. Boston: Little, Brown, and Company, 1975. 
Ono, Kent A. and John M. Sloop. "Commitment to Telos: A Sustained Critical Rhetoric." Communication Monographs 59 (1992): 48-60.

Phelan, Peggy. Mourning Sex: Performing Public Memories. New York: Routledge, 1997.

Probyn, Elspeth. Sexing the Self: Gendered Positions in Cultural Studies. New York: Routledge, 1993.

Ramet, Sabrina Petra. "Gender Reversals and Gender Cultures: An Introduction." Gender Reversals and Gender Cultures: Anthropological and Historical Perspectives. Ed. Sabrina Petra Ramet. New York: Routledge. 1-21.

Reiner, William. "To be Male or Female-That is the Question." Archives of Pediatric and Adolescent Medicine, 151 (1997): 224-225.

"Rethinking Gender Identity." MacLean's, 24 March 1997. 31.

Rich, Adrienne. “Compulsory Heterosexuality and Lesbian Existence.” Signs 5 (1981): 631-60.

Roan, Shari. "The Basis of Sexual Identity." Los Angeles Times, 14 March 1997. E1, E8.

Spanier, Bonnie. "Encountering the Biological Sciences: Ideology, Language and Learning." Writing, Teaching and Learning in the Disciplines. Eds. Anne Herrington and Charles Moran. New York: MLA, 1992. 193-212.

Wood, Julia T. "Gender, Relationships, and Communications." Gender Relationships. Ed. Julia T. Wood. Mountain View, CA: Mayfield P, 1996.

Received October 22, 1998

Final revision received October 5, 1999

Accepted October 25, 1999 